\title{
New Evaluation Horizons: Transportation Issues for the 21st Century
}

\author{
PATRICIA F. WALLER
}

\section{INTRODUCTION}

After beginning as a clinical psychologist, through an unlikely series of events and circumstances, I am currently involved in transportation research and policy. Traditionally, highway transportation has been dominated by professionals with technical backgrounds, primarily engineering, and the focus of concern has been vehicles and highways. Today, transportation issues are increasingly interfacing with other major societal concerns, and it is in this arena that technology and technological training are not enough.

Perhaps it is because the phenomena with which psychologists deal are not so precise as those in the physical or biological sciences, but whatever the reason, I believe that training in the social sciences provides a rigor that has special relevance for grappling with many of the emerging societal issues and problems in transportation.

Currently I am involved in a number of transportation areas that are dominated by engineers. I have no technical background whatsoever, and whether that is an advantage or disadvantage could be debated - certainly I often wish I knew much more than I do. Yet a background in the social sciences may be more relevant than is first apparent. While technology is an essential component of solving our transportation problems, it is not sufficient. In witnessing how public policy develops, I am increasingly impressed by what I will refer to as "The Ink Blot Phenomenon." By this I mean that, while technical expertise and technical data are useful, even essential, in arriving at public policy decisions, the final conclusions and recommendations developed are inevitably based on intuitive, informed intuitive, but intuitive nonetheless, interpretations that are not too terribly different from the process of interpreting ink blots.

By this I do not mean in any way to derogate either process. Certainly the interpretation of ink blots is determined to a large extent by the background and

Patricia F. Waller - Director, University of Michigan Transportation Research Institute, 2901 Baxter Road, Ann Arbor, MI 48109 
experience the observer brings to the task. By the same token, the interpretations made of the vast array of data and information made available to those responsible for formulating transportation policy are based on the background and expertise they bring to the task. Yet it is increasingly clear that ultimately our most important decisions boil down to a process of informed interpretation. Such interpretation is based on not just a careful consideration of all the available information but also tradeoffs among competing values. A current example is the issue of fuel economy and how it may be improved through regulation. Competing values include dependence upon foreign oil, environmental pollution, safety, economic competitiveness, equity across socioeconomic levels, political feasibility, traffic congestion, and individual freedom to choose. The bottom line is that some judgment must be made about what all the objective data really mean. Some judgment must be made about how competing values should be balanced and what should be done on the basis of the findings. We rarely have the luxury of having our data make these decisions for us.

\section{A SOCIAL SCIENTIST IN THE LAND OF TECHNOLOGY}

A brief description of the institute where I function will provide background to my further observations. The University of Michigan Transportation Research Institute, or UMTRI, began as the Highway Safety Research Institute, or HSRI. It was founded in 1965 , but in 1982, in recognition of the broad array of transportation issues being addressed by the Institute, the name was changed to UMTRI.

UMTRI includes research programs in seven major areas, ranging from Biosciences, which concerns impact injury mechanisms; Human Factors, which conducts studies of human perception, cognition, and risk-taking behavior; and Injury Analysis and Prevention, which conducts studies to assess effects of public policy on behavior and subsequent injuries; to Engineering Research, which studies truck ride characteristics, vehicle stability and controllability, and the Intelligent Vehicle Highway Systems (IVHS), and to which I will return; and the Office for the Study of Automotive Transportation, which conducts systems-oriented studies of socio-technological problems in the automotive industry. We also have a Marine Systems division that studies regulation of maritime transportation systems, and shipbuilding technology and economics; and a Statistical Research division, which administers the Center for National Truck Statistics; and conducts a national fatal truck accident survey, multivariate analyses of truck crash rates and crashworthiness issues, and studies on pre-collision factors related to collision avoidance. Our Transportation Data Center supports the work of these other divisions.

\section{Transportation-Its Need for Social Science Input}

Social changes are occurring in our society that will profoundly interact with our transportation system. We have scarcely begun to contemplate the impending 
changes resulting from our changing population demographics and labor force. While the problems posed will be formidable, available and emerging technology offer unprecedented opportunity for creative solutions.

Let me illustrate. UMTRI and the University of Michigan head one of five major university-based programs in IVHS, Intelligent Vehicle Highway Systems. For those of you who are not familiar with IVHS, let me explain. In 1956 Congress enacted legislation providing for the Interstate Highway System. The authorization for that system ended at the end of September of this year. It took 35 years to develop and implement the interstate highway system, and our highway transportation system was revolutionized in the process.

Today we have built just about all the highways we are going to build. Rather than turning more and more land into highways, we need to learn how to make better use of the highways we already have. And to accomplish this, the next major leap forward in highway transportation is IVHS. IVHS refers to smart cars/smart highways, that is, cars communicating with each other and cars and highways communicating with each other (Mobility 2000, 1990). IVHS will take at least as long to develop and implement as did the interstate highway system, and the impact will be at least as revolutionary.

Some of the overall objectives of IVHS include streamlining traffic operations, in part through better synchronization of traffic controls; informing drivers of upcoming congestion and providing information on alternative routes; replacing current toll collection with automated systems that eliminate the need for slowing and stopping; providing motorists with on-board "local yellow pages," that is, information on locally available food and lodging; and even automatically controlling vehicles to prevent collisions.

There are major issues surrounding the human interface of IVHS--not just the driver, but the larger issues of tort and product liability, economic aspects, user acceptance and willingness to pay, land use and values, among others. I will address only two areas where I believe IVHS has exciting potential for enhancing the human aspects of the transportation system, if social science expertise is brought to bear. These two areas are older drivers and drivers of heavy trucks.

\section{USING TECHNOLOGY TO ASSIST THE OLDER DRIVER}

The concept of IVHS grew out of the growing concern about congestion, but, if developed and implemented carefully, IVHS holds enormous promise for the older driver. Driver training and qualification are becoming much more critical as our driving population, along with the rest of us, is aging. While older drivers increase in numbers, younger drivers are decreasing. What are the implications of such demographic changes for our highway transportation system? We need to enable as many older drivers as possible to continue to meet their own transportation needs. There will simply not be enough younger ones to provide the necessary chauffeuring. How can we accomplish this? 
Our highway transportation system was never designed for the older user, either driver or pedestrian. When the older driver has difficulty with the system, some suggest that we simply remove him from the road. However, there are alternative solutions that have benefits for the entire society. These can be achieved through addressing driver licensing, vehicle design, and highway design, with a special focus on the older driver (National Research Council, 1988; Waller, 1991).

\section{Licensing}

The older driver is an increasing political force and is no longer content simply to be removed from the system. Moreover, it is in everyone's best interest that we do whatever we can to enable these older drivers to continue to function so long as they can do so safely. We need to know far more about evaluating older drivers for licensing. This information is needed for two purposes.

First, we need to identify problems and shortcomings so that, to the extent possible, we can devise strategies and measures to compensate for the problems. For example, we know that, with increasing age, vision problems develop (Mace, 1988; Bailey and Sheedy, 1988; Schieber, 1988). Most older people require more illumination to see as well as younger people. To a large extent this problem can be addressed through better signing and lighting for nighttime driving, but the issue is not a simple one. The improved headlighting necessary to enable an older driver to see adequately must not create problems for the older driver coming from the other direction. Older drivers, on the whole, have more difficulty with glare recovery, and headlighting must consider all older drivers.

The second reason for needing better measures in the evaluation of older drivers is that there comes a time when some older drivers must restrict or terminate driving. Ideally, we would allow them to continue to drive under conditions that are reasonably low hazard, but at the present time we have very little information about what these conditions are or how we determine an applicant's capabilities in relation to them. Thus, improved licensing evaluation is essential as our driving population ages (Waller, 1988).

\section{Vehicle Design}

Vehicle manufacturers are becoming increasingly interested in the older driver, although vehicle design still leaves much to be desired in this regard. For example, the design, lighting, and display of information and vehicle controls could be much improved for older users. Entrance and egress for older occupants should be further improved, as well as seating design. Occupant restraint systems are especially in need of re-design for older users. At the same time, manufacturers are hesitant about marketing specifically to older drivers. A car that becomes known as an "old folks' 
car" may not hold great appeal from a marketing standpoint, even for older consumers (Yanik, undated).

\section{Highway Design}

Finally, highway design must be reconsidered in light of the growing number of older users. Pedestrian signal timing is usually based on the assumption that pedestrians can move at the rate of four feet per second. In New York it was found that in one area there was an especially high rate of pedestrian fatalities. Closer investigation showed that they were older women-women who simply could not meet the traffic engineering criterion of moving four feet per second. Because the standards never considered their capabilities, they suffered the death penalty.

For older users, both drivers and pedestrians, it is not enough simply to measure the speed with which they can move. Older people, on the whole, require more time to process information and make a decision. As a result, highway information systems, signing, and traffic signals, must provide sufficient warning in a format readily intelligible to this user group. Highway design must be revised to include the actual capabilities of older users (Hauer, 1988; Deacon, 1988).

IVHS technology should be able to make major contributions to the mobility of the elderly by facilitating the driving task so as to enable more older people to continue to meet their own transportation needs. Thus, the new technology should hold promise, not just for the congested urban areas, but also for every nook and cranny of America. Social scientists can assist in understanding how technology may affect the user. The design and implementation of the technology can determine whether it is beneficial or harmful.

\section{TECHNOLOGY AND TOMORROW'S TRUCK DRIVER}

The second example of how I believe social scientists may contribute to the transportation field is illustrated by a recent experience. I was asked to help plan a symposium on heavy truck transportation. The symposium was to bring together civil and mechanical engineers so as to improve the fit between the vehicle and the highway. The ultimate goal was to increase productivity, an important goal in economic competitiveness.

Perhaps because I know so little about either civil or mechanical engineering, my immediate response to the inquiry was that if it is productivity you want to increase, you need to be including policy expertise. What is happening in truck transport is an illustration of what is happening throughout our economy. The workforce is changing drastically, and for trucking it has special implications.

Let me explain. The most reputable trucking companies that hire the best drivers are finding that the average age of their drivers is pushing fifty. Data clearly 
show that by the mid-fifties, driver performance begins to deteriorate and crash rate per mile driven begins to rise at an accelerating rate. This occurs even though most older drivers try to restrict themselves to the safest times and the safest conditions under which to drive. Commercial drivers, driving on a schedule, are not able to pick and choose their driving hours.

The driver cadre is aging out, but the available driver applicant pool is shrinking. Fewer younger drivers are coming along to replace our truck drivers. Furthermore, the job of truck driving is an extremely demanding one, and there is growing evidence that our younger population is less enamored of making their jobs their entire life. More and more, workers are asking for reasonable schedules and benefits (Johnston and Reed, 1988).

Traditionally, driving heavy trucks has been a male-dominated occupation, perhaps even a white male dominated occupation. But our labor force is changing. Between 1988 and the year 2000 the workforce will increase by about 16 percent, but there will be great variability in the proportion increases by racial and ethnic background. Blacks will increase their numbers by about 25 percent, Asians by 53 percent, Hispanics by 59 percent, White females by 20 percent, but White males will increase less than 9 percent (Fullerton, 1989). Any occupation that has relied heavily on a workforce that is predominantly white male needs to prepare for drastic change.

What are the implications of these forecasts? In the near future our major increases in population are coming from immigration, primarily from Central and South America and Asia. Something as basic as driver eye height is likely to be affected. Moreover, it is almost certain that we will need to attract more women into some occupations, including truck driving. This fact alone has broad implications for the work environment. In our society almost one-third of our children are living in single parent homes, with the parent usually female. Consequently, business and industry -including the trucking industry—need to become more concerned about family support programs, that is, programs that facilitate both child and elder care (Morrison, 1991: Johnston and Reed, 1988). In trucking, an industry that is highly fragmented, many, if not most, companies could not provide family support benefits on their own. Nevertheless, they could participate in multi-company or multibusiness plans, just as many currently do to provide health care benefits.

Emerging technology and the IVHS programs already used in commercial vehicle operation will lend themselves readily to what is needed. Real time monitoring of vehicle location, combined with on-board monitoring of vehicle equipment and emergency alert systems, can increase the safety and security of drivers, a concern for female drivers but important for males as well. Furthermore, careful scheduling and monitoring of drivers and vehicles can enable drivers to return home every day. A driver may take a vehicle one way during the first half of a shift, switch trucks with a driver coming from the other direction, and return home at the end of the shift. Driving may still occur over all three shifts, seven days a week, just as we 
currently employ workers round the clock in hospitals, public safety, and other areas. Such a system offers many advantages to the motor carrier industry, including a greatly expanded driver applicant pool, reduced on-road expenses, improved worker health and morale, and increased productivity.

While vehicle design and highway design are important and could be improved, attention to the human needs of workers will do far more to increase productivity in the short run than all the changes in nuts and bolts and metal and electrical circuits combined. Technology is essential, but it is only a part of what is needed. We need to use technology to enable workers and companies to collaborate more effectively to meet the rapidly changing characteristics and needs of our work force and thus to improve our productivity and our competitive position world wide.

\section{THE IMPORTANCE OF DATA}

Solutions to such problems are neither obvious nor simple and will require all the tools at our disposal. An absolutely essential ingredient is sound information. DATA!

When I began working in transportation, my director placed a strong emphasis on data, or in our field, traffic records. My reaction was, "How dull!" I had difficulty imagining anything more boring. However, I quickly recognized that all the issues that caught my imagination were ones that required better data than were then available. It is unlikely that we will ever capture the imagination of the public with the concept of data. We will never have a Presidential Commission on Traffic Data or a Traffic Records Awareness Week or a Surgeon General's Workshop on Traffic Data. Yet all our publicly acclaimed programs calling attention to the problem of drunken driving and leading to such national efforts amount to naught in the absence of good data systems. Data are the backbone of any successful program in highway safety, as well as most other fields.

For decades in much of transportation we have based public policy on "feel good" evaluations. Convicted drivers went through driver improvement clinics, afterward maintaining that they learned a lot, and everyone felt good about the programs. Unfortunately, when programs were evaluated objectively, they were not nearly so effective as everyone had believed. Yet this approach persists in many areas. It is even argued that if we make the offender pay for the program, it really isn't costing anything!

In addition to the usual built-in inertia that resists any change, there are vested interests that would prefer that data not become available. In some quarters the logic seems to be that if you cannot prove that there is a problem, that proves there is not one. If data are then provided showing there is a problem, the news is considered less than welcome. 


\section{DATA LIMITATIONS}

Of course, data have their limitations. The information obtained is determined largely by the way the data collection system is designed and executed: For example, for years in North Carolina there was no problem whatsoever with mopeds. Our crash report form did not provide for moped as a vehicle type. Consequently investigating officers classified them as pedal cycles or as motorcycles. Once the form was changed to include mopeds, a moped problem immediately developed.

Evaluation specialists probably know better than anyone else how the way a question is asked can determine the answer. Crash report forms provide an excellent illustration of this phenomenon. Examination of state crash report forms shows little space to record defects in the highway environment, and few investigating officers have training in. highway or traffic engineering to enable them to make informed judgments about the adequacy of the highway environment. Report forms likewise have little space and few options to record possible problems with the vehicle, nor do most investigating officers have training in vehicle engineering or how to identify vehicle defects. In contrast, most crash report forms have a wide array of options to choose from in deciding what the driver may have done wrong. If investigating offices have any training at all, it is likely to be in traffic law. Then, we find that most crashes are caused by-driver error!

Even studies that involved multidisciplinary crash investigation teams came to the same conclusions (Joscelyn and Treat, 1976). These findings are widely quoted, so that almost everyone knows that something like 80 to 90 percent of crashes are caused by driver error. Yet closer examination of these studies reveals that the way the questions were asked almost guaranteed the conclusion. If a highway met existing standards, the problem could not have been the highway. If the vehicle met manufacturer's standards, the problem was not the vehicle. THEREFORE, the problem had to be the driver.

By this logic, would it not be the case that if the driver held a valid driver license, he or she had met existing standards, so it could not possibly be the driver? It may be pointed out that driver licensing standards are not very stringent. True. But standards for highway design are based primarily on performance measures obtained from young males. Is that an appropriate criterion for the wide array of drivers on our highways? It has been argued by at least one highway engineer that if most states define the legal limit for drunken driving as 0.10 percent blood alcohol concentration $(\mathrm{BAC})$, then should we not be designing our highways so that they may be safely maneuvered up to 0.09 percent BAC? (Hall, 1983) As for vehicle design, anyone who has tried to read the dashboard in a rental car at night, while wearing bifocals, may have some opinions on the adequacy of vehicle design for the whole range of our driving population.

Studies concluding that a crash is caused by "driver inattention" or "going too fast for conditions" are not necessarily very helpful. By definition any crash infers 
that someone was going too fast for conditions, but that bit of information is not necessarily useful in designing countermeasures.

Data are essential, but the data must be better than much of what we have. currently available. One last example on the importance of good data. Years ago on a major highway it was observed that an overrepresentation of crashes was found on highway stretches characterized by "downgrades of modest curvature in wet weather." Closer examination showed that "these particular road segments were not sufficiently superelevated to provide proper drainage." The observation was possible because of the excellent data system that included detailed information on both crashes and highway locations. The situation was corrected, and the crashes ceased (Dunlap et al., 1974, in Haight et al., 1976). Yet it is almost certain that for each of those individual crashes a driver was charged with something like, "Going too fast for conditions," and it was concluded that the problem was driver error.

Most highway systems are not so carefully monitored. It would be difficult to guess how many drivers have been charged because of the lack of data systems that would enarle much more effective interventions than simply issuing tickets.

\section{ORGANIZATIONAL AND INSTITUTIONAL BARRIERS TO EFFECTIVE EVALUATION}

Progress, or lack of it, may be affected by the organization and structure of our scientific community, including our universities, as well as the greater society, both public and private sectors. Our universities, and, to a large extent, the scientific community, are defined by disciplines, a system that has undoubtedly proved of value. But it should be asked whether this approach has outlived its usefulness and is now stifling some much-needed progress. Our most significant societal problems today transcend disciplines, transcend institutions and government agencies. Yet the persisting structures inhibit effective collaboration and true interdisciplinary and interagency cooperation. We are becoming more and more bogged down by the system itself.

The most critical problems facing our nation today lie at the interfaces of disciplines, agencies, authorities, and interest groups. Our illiteracy rates are strangling our businesses and industries and in turn our competitiveness. Our aging population cries out for better design of both the physical and the social environment, as well as strategies on how to make better use of the talent and expertise possessed by this age group. The poisoning of our planet increases at an accelerating rate, crossing jurisdictional lines, both local and international. The increasing fragmentation of family structure underscores the growing need for societal programs to assist people in need-not programs that cripple them by making them slaves of an outmoded welfare system, but rather programs that build their competence and self esteem to enable them to become productive members of society. These are everyone's problems, but no one's responsibility. 
A recent report pointed out that the largest group of people living in poverty in our society today is children under five (Bureau of Census, 1991). Subsequently the MacNeil-Lehrer News Hour had a few experts discussing the question of whether we as a society love our children. One of the participants pointed out that if you look at the demographics of our population today, we are going to need every child that is coming along to be healthy, well educated, and responsible. This is the generation that will be in charge and will have responsibility for looking out for the baby boomers in their dotage. How well are we grooming these little ones for the responsibilities they will have placed upon them? How well can we expect them to perform when their turn at bat comes?

\section{THE SHORTSIGHTEDNESS OF SHORT TERM EVALUATION}

As a society we are increasingly taking a short-term view. We see ourselves as saving money by reducing investment in health care and education. We rank low among modern industrialized nations in what our children are achieving in school (Henry, 1992). We have one of the highest infant mortality rates in the modern industrialized world (United Nations, 1988). Between 1984 and 1989 the life expectancy of our black male population steadily declined (Monthly Vital Statistics, 1992). We solve our social problems by building more prisons. Unlike health and education, here we rank number one. We have the highest proportion of our population in prison of any modern industrialized nation in the world, now having surpassed even South Africa and what was the U.S.S.R. (The Futurist, 1991).

Are Americans really so much worse than people elsewhere in the world? Only Iraq surpassed us this past year in the number of executions of persons who committed crimes while still a minor. We have more young black males of college age in prison than in four-year colleges. Is anyone conducting comprehensive evaluations of the implications of these social policies? Is it more economical to maintain people in prison than to invest in preventive efforts at an earlier age? Do such policies really enhance our economic competitiveness? Is this the kind of society that we want our children and grandchildren to inherit, and can we face them with pride as we turn it over to them?

\section{THE NEED FOR BROADER MORE COMPREHENSIVE EVALUATION}

What must be done to extend evaluation beyond the bottom line of the next fiscal quarter? How can evaluation contribute to society's comprehension of the longer term consequences of the decisions we make and the options we choose today? How can we transcend traditional boundaries that separate disciplines, government agencies, businesses and industries, and the myriad special interest groups to enable all 
of us to recognize that we either hang together or we hang separately? We need the experience and special skills of all of us to be able to fully define the scope of the problems we face and how to design appropriate evaluations that effectively inform the decision makers.

\section{CONCLUSION}

The theme of this conference is New Evaluation Horizons, with a focus on Science and Technology, the Environment and Infrastructures, and Business and Economic Competitiveness. Illustrations of evaluation issues in all these areas abound in transportation. Yet efforts to address these issues inevitably run into organizational barriers. Let me give examples.

IVHS is highly dependent upon emerging science and technology, but also requires a redesign and upgrading of the highway infrastructure. The success of our IVHS program has grave implications for U.S. business and industry, both directly in terms of product design and manufacturing and indirectly in terms of the quality of our transportation system. Success is also inextricably tied to cooperation between government and industry and among various industries.

Yet our governmental and legal structure is such that there are strong barriers to such collaboration. These barriers do not exist, or at least do not exist to the same extent, for our global competitors. Both Japan and Europe are years and hundred of millions of dollars ahead of the U.S. in developing IVHS. Japan has completed marketing surveys in the U.S. One scenario is that one of these days Southern California will come to a grinding halt and the people will be desperate. But Japan will step forward, saying, "Not to worry, just sign here and we will begin installation of equipment next week!"

We are struggling to engender industry collaboration without running into legal problems. Even if the legal barriers were to disappear tomorrow, our corporate mentality is so imbued with historical baggage that it is difficult to function effectively. Government also does not know how to respond to the challenge. The recently passed surface transportation act is providing large sums to address IVHS, but most of the dollars are earmarked for demonstration programs that are designed to do little more than implement known practices and technology, some of which has been around for decades. There is no recognition of the need to fund basic research to address both new materials and technologies and new societal structures to meet the unprecedented social issues.

If we are to become truly competitive in meeting what is the most exciting challenge ever to confront the field of transportation, we are going to have to change our whole way of thinking and doing business. We are not simply re-designing highway transportation-we are on the verge of re-inventing it. Traditionally we have thought of mobility on our highways as a series of tradeoffs-we, as a society, are willing to pay about 45,000 lives and several million disabling injuries each year 
in exchange for the mobility we enjoy on our highway transportation system. Likewise, we are willing to pay less clearly defined costs in air pollution, contributing to the destruction of the earth's ozone layer, with consequences not fully comprehended. We know that we could reduce our costs in both injury and air pollution through significant reductions in travel, but as a nation we are unwilling to consider such an option. We would rather pay the costs.

Transportation is only one illustration of the challenges facing our society. But transportation clearly illustrates how technology is outrunning social science. We are becoming increasingly captured by the beauty and possibilities of technology without paying sufficient attention to the people dimension. The bottom line has got to include people costs, long term people costs, as well as quarterly financial earnings.

More than ever before, those responsible for evaluation of programs and options must assume responsibility for going beyond what most politicians and administrators are requesting. There are leaders in both industry and government who recognize the potential human implications and costs of our short term vision, but they need our help. If we are to emerge as a strong competitive caring society, leaders with longer-term vision must be reinforced by sound objective evaluations conducted by experts who can spell out clearly the destructive consequences of focusing only on the technology and on limited short-term effects of decisions. The participation and leadership of evaluation specialists are essential.

\section{REFERENCES}

Bailey, I.L. and Sheedy, J.E. (1988). Vision screening for driver licensure. In Transportation in an Aging Society, pp. 294-324. Washington, DC: National Research Council.

Deacon, J.A. (1988). Potential improvements in roadway delineation for older drivers. In Transportation in an Aging Society, pp. 253-269. Washington, DC: National Research Council.

Dunlap, D.F., Fancher, P.S., Scott, R.E., MacAdam, C.C., and Segal, L. (1974). Influence of Combined Highway Grade and Horizontal Alignment on Skidding. Ann Arbor, MI: Highway Safety Research Institute.

Fullerton, H.N. Jr. (1989). New labor force projection, spanning 1988 to 2000. Monthly Labor Review, (November), 3-12.

The Futurist. (1991). U.S. leads world in jail population. The Futurist, (July-August), 47.

Haight, F., Joksch, J., O'Day, J., Waller, P., Stutts, J., and Reinfurt, X. (1976). Review of Methods for Studying Pre-Crash Factors. Washington, DC: National Highway Traffic Safety Administration.

Hall, T. (1983). The responsibility of the civil engineer to the drinking driver. In M.E. Lipinski (ed.), The Role of the Civil Engineer in Highway Safety, pp. 113-120. New York: American Society of Civil Engineers.

Henry, T. (1992). U.S. teens lag in math, science. In Ann Arbor News, February 6, 1992, From Associated Press, Washington, DC.

Hauer, E. (1988). The safety of older persons at intersections. In Transportation in an Aging Society, pp. 194-252. Washington, DC: National Research Council.

Johnston, W.B. and Reed, D. (1988). The Shortage of Drivers and Mechanics. What Can Be Done? Indianapolis; IN: Hudson Institute. 
Joscelyn, K.B. and Treat, J.R. (1976). Tri-Level Study of the Causes of Traffic Accidents, Final Report. Washington, DC: National Highway Traffic Safety Administration.

Mace, D.J. (1988) Sign legibility and conspicuity. In Transportation in an Aging Society, pp. 270293. Washington, DC: National Research Council.

Mobility 2000 (1990). Intelligent Vehicles and Highway Systems. College Station, TX: Texas Transportation Institute.

Monthly Vital Statistics Report. (1992). Monthly Vital Statistics Report, 40(8[S]2), 4 (January 7).

Morrison, P.A. (1991). Congress and the Year 2000: A Demographic Perspective on Future Issues. Santa Monica, CA: RAND.

Schieber, F. (1988). Vision assessment technology and screening older drivers: Past practices and emerging techniques. In Transportation in an Aging Society, pp. 325-378. Washington, DC: National Research Council.

United Nations. (1990). 1988 Demographic Yearbook.

U.S. Department of Commerce. (1991). Poverty in the United States: 1990. In Current Population Reports, Series P-60, No. 175,p. 3.

Waller, P.F. (1988). Renewal licensing of older drivers. In Transportation in an Aging Society, pp. 72-100. Washington, DC: National Research Council.

Waller, P.F. (1991). The older driver. Human Factors, 33(5), 499-505.

Yanik, A.J. (Undated). Barriers to the Design of Vehicles for Mature Adults. 